\title{
Continuous Dynamic Mapping of Cranial Nerve Pathways and Long Tracts Inside the Brainstem: Useful Technique of Intraoperative Neurophysiological Monitoring
}

\author{
Volodymyr I. Smolanka ${ }^{1}$, Andrey V. Smolanka ${ }^{2}$, Oleksandr S. Sechko ${ }^{2}$, Olga S. Herasymenko ${ }^{1}$ \\ ${ }^{1}$ Uzhhorod National University, \\ 3 Narodna Sq., 88000 \\ Ukraine \\ ${ }^{2}$ Uzhhorod Regional Clinical Centre of Neurosurgery and Neurology, \\ 24 Peremoha Str., 88018 \\ Ukraine
}

Received: February 13, 2021. Revised: July 3, 2021. Accepted: July 26, 2021. Published: July 30, 2021.

\begin{abstract}
Surgery of intrinsic brainstem lesions is extremely dangerous, consequently the knowledge of anatomy and safe entry zones is extremely important. The technological progress was achieved with the widespread clinical use of intraoperative neurophysiological monitoring (IONM) which has proven to further improve the safety of operating on intrinsic brainstem lesions. The relevance of the study is conditioned by the fact that the tumor alters the normal anatomy and distorts the location of well-known landmarks and structures. In this regard, this paper is directed at identification of the placement of conductive pathways in the thickness of the brain stem and directly in the depth of the lesion (in the tumor or cavern), respectively to the surgical manipulations aimed at injury prevention. The results were achieved by a retrospective review of medical reports. The paper represents the results of surgical treatment of $\mathbf{4 2}$ patients with brainstem lesions, reviews the localization of the lesion and neurological status of patients, describes available methods of intraoperative monitoring (IOM) and on-line techniques for the brainstem surgery. The materials of the paper are of practical significance for the development of brainstem surgery with IONM modifications for wider and more comfortable use by neurosurgeons.
\end{abstract}

Keywords-intrinsic brainstem lesions; surgery; medical report; brain stem surgery.

\section{INTRODUCTION}

Surgery of intrinsic brainstem lesions consider extremely $N_{\text {dangerous. One of the greatest contributions to anatomical }}$ basis of brainstem surgery with description of safe entry zones into the brainstem were works by Bricolo, Hoshide, and Fonseca [1-3]. Knowledge of anatomy and safe entry zones are extremely important, but it is well known that the tumor alters the normal anatomy and distorts the location of wellknown landmarks and structures. The technological progress was achieved with the widespread clinical use of intraoperative neurophysiological monitoring (IONM) which has shown to further increase the safety of operating on intrinsic brainstem lesions. C. Strauss, N. Morota, and S. Mueller described the distortion of normal surface anatomy in brainstem lesions and the necessity to determine the surgical entry to the brainstem relying on surface mapping [4-8].

All of the safe entry zones described in last 30 years were summarized in the article by Yang et al. [9]. Authors point out an interesting fact - most of the safe zones were obtained as a result of anatomical studies on cadaver, where, of course, the demonstration of functional polysynaptic communication is impossible. Therefore, the use of multimodal IONM in brain stem surgery is extremely important, since all the nuclei and pathways could be clearly identified even in the setting of changed anatomy due to tumor growth [8]. Brainstem mapping is the gold standard in determination of safe entry zone, but myelotomy is one of the first steps of surgical intervention. Other monitoring techniques (TcMEP's, CoMEP's and SSEPs) provide a real-time information by performance result for the surgeon, during resection of brainstem lesion. However, is necessary to identify the 
placement of conductive pathways, respectively to the surgical manipulations in order to prevent injury of them.

\section{MATERIALS AND METHODS}

In this article we report the results of surgical treatment of 42 patients with brainstem lesions (brainstem tumors - 30, brainstem cavernous malformations - 12), which were operated on in our Centre over the past three years (from 2016 to 2019) with the use of multimodal IONM. The results were attained by a retrospective review of medical reports. We reviewed the localization of the lesion, neurological status of patients (on admission, on discharge and on last follow-up), changes of neurophysiological data during surgery, and the extent of resection. Anesthesia was induced with bolus doses of diprofol $(3 \mathrm{mg} / \mathrm{kg}) /$ phentanylum $(0.2 \mu \mathrm{g} / \mathrm{kg})$ and further maintained with diprofol $(4-7 \mathrm{mg} / \mathrm{kg} / \mathrm{h})$ and phentanylum $(0.2-$ $0.3 \mu \mathrm{g} / \mathrm{h})$. The muscle relaxant atrocuronium $(0.3-0.6 \mathrm{mg} / \mathrm{kg}$ bolus) or dithylin ( $1 \mathrm{mg} / \mathrm{kg}$ bolus), was administered for intubation purposes only.

Intraoperative monitoring system (Nim Eclipse E4, 32 channel system [Medtronic]) was used for multimodal IONM. Standard IONM modalities were used in all cases: TOF for monitoring neuromuscular transmission; transcranial motor evoked potentials (TcMEPs) for monitoring of the corticospinal tract; corticobulbar motor evoked potentials (CoMEPs) for monitoring of the cranial nerve pathways; somatosensory evoked potentials (SSEPs) for monitoring of the spinothalamic tract; free-running electromyography (fEMG) muscles for monitoring cranial nerve, nuclei and distal muscles extremities; brainstem mapping (BSM) for localization of safe entry zone into the brainstem. The use of other modalities (visual evoked potentials (VEPs), brainstem auditory evoked potentials (BAEPs), blink reflex, masseter reflex and laryngeal adductor reflex) was tailored by the localization of the tumor.

In addition to standard techniques, we performed continuous dynamic mapping with a monopolar ring stimulus adapter [Medtronic] for suction and for identification of cranial nerve pathways and long tracts inside the brainstem. This technique is a modification of the brainstem mapping first described by C. Strauss and N. Morota [4, 7] and mapping of the motor fibers described by F. Sala [10]. Parameters of this modality are described in Table $\mathbf{1}$.

TABLE I. IDENTIFICATION: CONTINUOUS DYNAMIC BRAINSTEM MAPPING

\begin{tabular}{ll}
\hline General characteristics & \\
\hline Modality & low stim \\
Type & current \\
Polarity & normal \\
Cathode & $\begin{array}{l}\text { monopolar ring stimulation } \\
\text { for suction } \\
\text { monopolar needle in upper } \\
\text { forehead } \\
\text { Anode }\end{array}$ \\
Frequency & $1.0-3.0 \mathrm{~Hz}$
\end{tabular}

\begin{tabular}{ll} 
Duration & $0.5 \mathrm{msec}$. \\
Cranial nerve pathways & \\
Intensity & $0.5-2 \mathrm{~mA}$ \\
Pulse & single \\
Long tracts (CST) & \\
Intensity & $0.5-4 \mathrm{~mA}$ \\
Pulse & train-of-three \\
\hline
\end{tabular}

Critical changes in monitoring data were considered to be $50 \%$ decrease in amplitude with increase of the stimulation intensity to elicit a response of more than $20 \mathrm{~mA}$ for TcMEPs and CoMEPs, $50 \%$ decrease in amplitude and more than $10 \%$ lengthening of latency for SSEPs. Signal loss and delay in latency of peaks (III and V) for BAEPs. Presence of activity type trains (A, B, and C) for free-running electromyography (EMG).

The removal volume was assessed by four groups: gross total resection (GTR), subtotal resection (STR), part resection (PR), near total resection (NTR) by evaluating computed tomography (CT) or magnetic resonance imaging (MRI) in the early postoperative period (at less than 72 hours). Neurological deficit was assessed according to generally accepted scales. For assessment of oculomotor nerves function we used the scale described by T. Sekiya [11]. Facial nerve function was assessed according to J.W. House and D.E. Brackmann [12] scale. Caudal nerve's function was examined in accordance with Dysphagia outcome and severity scale [13]. McCormick scale was used to assess the combination of sensitive and motor disorders in extremities [14]. Quality of life in patients with brainstem tumors was assessed using Karnofsky Performance Scale [15].

\section{RESULTS}

A total of $42(100 \%)$ surgical resections of the brainstem lesions were performed. Of these, $30(71 \%)$ patients had tumors and $12(29 \%)$ patients - cavernous malformations (Table 2). All patients were divided into four groups according to localization of the lesion: midbrain $-7(17 \%)$, pons - $22(52 \%)$, ponto-medullary junction $-7(17 \%)$, medulla oblongata $-6(14 \%)$. Majority of patients in our series had neurological deficit before surgical intervention (27 patients, 64\%). On discharge we noted a new long-tract deficit in 13 cases $(31 \%)$ and new cranial nerves' deficit in 9 cases (21.4\%). On last follow-up three patients $(7.14 \%)$ had isolated cranial nerve deficit and only one patient $(2.3 \%)$ had longtract deficit. Three patients $(7.14 \%)$ died. Their data was included in the analysis on admission and on discharge, but they were excluded from the analysis on last follow-up. Gross total resection was achieved in 26 cases $(62 \%)$, near total resection - in 3 cases (7\%), subtotal resection - in 8 cases $(19 \%)$, partial resection - in 5 cases $(12 \%)$. All cavernous malformations were resected completely, so after their exclusion from analysis the rate of GTR in brainstem tumors was $46.7 \%$. The significant increase in performance 
Karnofsky Scale [15] was registered on last follow-up (Table 2).

TABLE II. INTRAOPERATIVE MONITORING AND NEUROLOGICAL OUTCOME

\begin{tabular}{lcccc}
\hline $\begin{array}{l}\text { Localizatio } \\
\text { n }\end{array}$ & $\begin{array}{c}\text { Midbrai } \\
\mathbf{n}\end{array}$ & Pons & $\begin{array}{c}\text { Ponto- } \\
\text { medullar } \\
\text { y junction }\end{array}$ & $\begin{array}{c}\text { Medulla } \\
\text { oblongat } \\
\text { a }\end{array}$ \\
\hline Patient & $(\mathrm{n}=7$, & $(\mathrm{n}=22$, & $(\mathrm{n}=7$, & $(\mathrm{n}=6$, \\
population & $17 \%)$ & $52 \%)$ & $17 \%)$ & $14 \%)$ \\
\multicolumn{5}{c}{ Clinical examination on admission } \\
$\begin{array}{l}\text { Pre-op } \\
\text { deficit }\end{array}$ & $6(86 \%)$ & 10 & $5(71 \%)$ & $6(100 \%)$ \\
Average & 80 & $91 \%)$ & 84 & 72 \\
KPS & & & &
\end{tabular}

\begin{tabular}{lcccc} 
New deficit & \multicolumn{5}{c}{ Clinical examination on discharge } \\
& $4(57 \%)$ & 11 & $4(56 \%)$ & $3(50 \%)$ \\
Average & 77 & 86 & 80 & 70 \\
KPS & \multicolumn{5}{c}{ (50\%) } \\
New deficit & $1(14 \%)$ & $2(8 \%)$ & - & $1(17 \%)$ \\
Average & 88 & 98 & 97 & 80 \\
KPS & & &
\end{tabular}

\begin{tabular}{lcccc} 
Death & \multicolumn{5}{c}{$\begin{array}{c}2(9 \%) \\
\text { Critical IOM changes }\end{array}$} \\
MEPs & $3(43 \%)$ & $\begin{array}{c}5 \\
\text { ComePs }\end{array}$ & $2(29 \%)$ & $3(50 \%)$ \\
CoME) & $2(29 \%)$ & $\begin{array}{c}3 \\
3\end{array}$ & $3(43 \%)$ & $1(17 \%)$ \\
SSEPs & $2(29 \%)$ & $\begin{array}{c}5 \\
5\end{array}$ & $1(14 \%)$ & $2(33 \%)$
\end{tabular}

\begin{tabular}{|c|c|c|c|c|}
\hline \multicolumn{5}{|c|}{ Identification of nuclei and tracts } \\
\hline BSM & $4(57 \%)$ & $\begin{array}{c}22 \\
(100 \% \\
)\end{array}$ & $7(100 \%)$ & $6(100 \%)$ \\
\hline $\begin{array}{l}\text { InBSM } \\
\text { (CBT) }\end{array}$ & $5(71 \%)$ & $\begin{array}{c}22 \\
(100 \% \\
)\end{array}$ & $7(100 \%)$ & $6(100 \%)$ \\
\hline $\begin{array}{l}\text { InBSM } \\
\text { (CST) }\end{array}$ & $4(57 \%)$ & $\begin{array}{c}10 \\
(45 \%)\end{array}$ & $2(29 \%)$ & $4(66 \%)$ \\
\hline \multicolumn{5}{|c|}{ Extent of resection } \\
\hline GTR & $3(43 \%)$ & $\begin{array}{c}18 \\
(82 \%)\end{array}$ & $4(57 \%)$ & $1(17 \%)$ \\
\hline NTR & $1(14 \%)$ & - & - & $2(33 \%)$ \\
\hline STR & $3(43 \%)$ & - & $2(29 \%)$ & $3(50 \%)$ \\
\hline PR & - & $\begin{array}{c}4 \\
(18 \%)\end{array}$ & $1(14 \%)$ & - \\
\hline
\end{tabular}

Brainstem mapping was used in 40 patients $(95.2 \%)$, where the safe entry zone was found. 7 patients at the midbrain lesions 4 cases of successful identification of nucleus IV. 22 patients at the pons lesions identified the localization of two or more nuclei in each patient: 6 cases - nucleus $\mathrm{V}$, in 16 cases VI; in 20 cases - nucleus VII was identification, in 3 cases from this group the responses were separately recorded from the orbicularis oculi muscle proximal to the lesion and laterally from the orbicularis oris; nuclei IX/X were recorded in 12 cases. 7 patients at the ponto-medullary junction localization and 6 patients with medulla oblongata were identified in 8 cases - nuclei IX/X, 3 cases - nucleus XI and 4 cases - nucleus XII. These patients without the concomitant negative EMG activity and changes during the first 5 minutes in CoMEPs after myelotomy.

As for mapping at the Intrinsic of the brainstem we used in 40 cases (95.2\%) the modified Continuous dynamic mapping in lesions tissues and in brainstem parenchyma where we received responses from all identified BSM cranial nuclei. Also was managed to obtain a new additionally responses: in the midbrain in 3 cases from nucleus III; in 4 cases at the pons - from nuclei IX/X; in the ponto-medullary junction and in the medulla oblongata lesions -2 cases from nuclei IX/X and 3 cases from nucleus XII. 20 patients $(47.6 \%)$ with identification of long tracts: 3 cases from muscles of lower limb of the contralateral side; 16 cases from muscles upper and lower extremities contralateral side; 1 case from muscles upper and lower extremities from both sides. These patients had intraoperative changes fEMG, transcranial motor evoked potentials (TcMEPs), CoMEPs and SSEPs.

In 19 cases (45.2\%) where initial baseline TcMEPs were attained no changes were recorded and none of those patients had new neurological deficit. In 2 patients (4.8\%) with severe preoperative motor deficit baseline TcMEPs could not be recorded, but no new deficit was noted after surgery. 21 patients $(50 \%)$ had intraoperative TcMEPs changes, but new motor deficit on discharge was present exclusively in cases $(\mathrm{n}=13,30.9 \%)$ where TcMEPs decreased more than $50 \%$. Accordingly, 12 patients $(28.5 \%)$ with identified the long tracts had a new neurological deficit on discharge McCormick I-II and recovered in the last follow-up. But only one patient could not recover to preoperative level on last follow-up. In that particular case $(\mathrm{n}=1,2.3 \%)$ MEPs amplitude decreased by more than $80 \%$ and did not identify the long tracts, the patient developed severe hemiparesis McCormick 3, on last follow-up [14].

In 22 patients CoMEPs were unchanged from baseline, 2 patients $(4.8 \%)$ with severe cranial nerve deficit on admission we were unable to register the initial level of CoMEPs from one side and 9 cases $(21 \%)$ decreased by $35 \%$. In other all cases $(n=9,21.4 \%)$ where CoMEPs decreased more than $50 \%$, patients had new deficit on discharge. The average degree of expression of neurological deficits in the ocular motor - mild grade, swallowing - I-II grade, J.W. House \& D.E. Brackman [12] - II-III-IV. In the last follow-up was registered in 3 cases (7.14\%) of cranial nerves deficit in one patient with facial nerve $\mathrm{H}-\mathrm{B} \mathrm{V}$, second of the facial nerve deficit $\mathrm{H}-\mathrm{B}$ VI and only one patient had mild grade oculomotor nerve palsies. Critical SSEPs changes were registered in 10 cases (24\%). A decrease in SSEPs amplitude more than 50\% was recorded in 6 out of 10 cases. All of them did not have a new neurological deficit on discharge. Lengthening of latency by more than $10 \%$ was recorded in 4 cases with hemihypesthesia on discharge and only one of them with hemihypesthesia 
persisted on last follow-up. BAEPs were monitored in 29 patients $(69 \%)$ for pons and ponto-medullary lesions. In two cases were lost completely, but without hearing impairment. VEPs were used for midbrain lesions in 7 patients (16.7\%) with no significant changes and no corresponding visual disturbances in patients. Laryngeal adductor reflex was performed in several cases $(n=3,42.8 \%)$ for ponto-medullary lesions, without any dynamic changes and patients without new deficit. Blink reflex $(\mathrm{n}=12,55 \%)$ and masseter reflex $(\mathrm{n}=10,45 \%)$ were researched in patients for pontine lesions. In one case there was a total loss of responses, and we registered a permanent new deficit of facial musculature [12].

\section{DISCUSSION}

Available methods of IOM can be divided into on-line monitoring and identification [10, 16, 17]. Regard to the online monitoring techniques is all evoked potentials and reflexes, when stimulation and recording these takes place outside the surgical action zone $[16,18]$. They have a very important role in representation the result of actions in dynamics and enable for correction of surgical tactics and actions of the neurosurgeon. At the beginning of the surgical intervention, record the baseline of evoked potentials and reflexes, performed mandatory control before the main step. Of course, when we had changed the baseline evoked potentials or reflexes during the surgery, stopped any manipulations and then irrigation was performed with warm solution and changed further tactics. Most popular is TcMEPs, CoMEPs and SSEPs. Analysis of the alternations of changes SSEPs and TcMEPs in articles Philipp J. Slotty and Krzysztof Majchrzak [19-22] shows the importance of the use for infratentorial surgery for monitoring purposes by long track. Motor and other brainstem injuries sparing the medial lemniscus can occur without deterioration of SSEPs that cover $<20 \%$ of brainstem area $[18,23]$. Special attention should be for SSEPs during bleeding or vascular traction, also, anatomical features of the area surgery, dorsal or ventral brain stem surface, as described in Xuesong Liu and al [24]. The experience described in the numerous articles demonstrates the effectiveness of CoMEPs use to achieve on-line monitoring of control to functional integrity cranial motors fibers [18, 25-30], if followed at the all rules, the registration can be without interruption the surgeon's work [16, 27]. In recent years, the use of different types of reflexes became frequently [27, 31-34], oppositely BAEPs technique which was basic in the $90 \mathrm{~s}$ for brainstem monitoring $[35,36]$, but in our time gives only $20 \%$ of the brainstem area $[10,26]$.

Identification is BSM, given the literature the main function is to identify the cranial nuclei and safe zones in the structure on the floor of the fourth ventricle brainstem $[4,7,16,27]$. But has several disadvantages including frequent interruption of the surgical procedure, the limitation of its use to the dorsal brainstem and fourth ventricle, with limited use in ventral or lateral brainstem operations and etc. $[17,18]$. However, the possibilities of the method are gradually expanding and improving to achieve a better result. In 2000, an article by Tetsuji Sekiya with co-authors [37] described the technique of recording and mapping the ocular motor nuclei in midbrain surgery and pineal areas with elements of deep mapping of midbrain tissue and the main anatomical features of this zone. Also, in 2000, Vedran Deletis [38] proposed a novel algorithm in brainstem surgery that consisted of three techniques mapping the bottom of the fourth ventricle for Cranial Nuclei III-XII pairs, Continuous Monitoring of the Corticospinal Tract by Recording D Wave in the Spinal Cord and Neurophysiological Localization of the Corticospinal Tract Within Cerebral Pedunculi in combination with epidural electrode D waves. And in 2010 was described their experience of registration in the tumor tissue of the brain stem responses from the muscles enervated by cranial nerves [18]. In 2015, Francesco Sala and others [16] described the full methodology BSM Identification of the Cranial Motor Nerve Nuclei and advanced Identification of the Corticospinal Tract at the Level of the Cerebral Peduncle Through Direct Stimulation. Based on this experience, we carried out surface mapping of the brainstem all surface and/or altered tissue necessary for our work.

Main aspects of the technique. It is extremely important not to start mapping on the structures in the presence of significant activity EMG, as it is not possible to get a clear response from certain nuclei. Irrigation by warm solution has a positive effect on EMG [39]. Before BSM, we disabled other modalities to reduce activity artifacts other than fEMG to conduct direct control of the stimulation, for register an artifact from the stimulus and specific activity [40]. Our first step was BSM, we used preferably the monopolar concentric hand-held stimulator, with an initial stimulus intensity of 0.5 $\mathrm{mA}$, for reduces the time to identify, versus the recommended $2 \mathrm{~mA}[5,6,8,16,27]$. As for the cavernous malformations, where changes on the surface were visualized, we followed the standard technique [41], with regard to data BSM. For deep vascular lesions, the stimulation intensity was not increased. The tumors we did not decrease the stimulation intensity below $0.5 \mathrm{~mA}$ (the patient which neurological dysfunction before the surgery or high density of tumor tissue consistency) we conversely increased add by $0.1 \mathrm{~mA}$. In all cases where BSM was performed, we obtained responses that allowed to identified the safe entry zones, so we modified the classical safe entry zones [9, 42, 43] for each patient individually, with regard to data BSM [16]. Bypassing the functionally active areas, the surgeon performed an incision of brainstem in the non-functional zone, without the concomitant negative activity fEMG and changes during the first 5 minutes in control CoMEPs after myelotomy.

Second step, for subsequent entry into the intrinsic parenchyma, we used monopolar ring stimulus adapter for suction, since the suction always uses during surgery. So, surgeon doesn't have to waste time change stimulator and constant stops for mapping [44]. In addition, if necessary, change the aspirator (technical stagnation or need another size) is not a problem, change it, without changing the 
stimulator itself. For avoid to artifacts, it is necessary to isolate the major part surface of the aspirator. We have separated this stimulation technique under the name "Intrinsic brain stem mapping" because it has certain differences from the classical BSM. iBSM is used to map the conductive pathways in the thickness of the brain stem and directly in the depth of the lesion (in the tumor or cavern). We used current intensity parameters were obtained and fixed after the mapping for some or other nuclei on the surface, thusly we obtained an initial level to identify the conductive paths of the corresponding nucleus. Performing removal of a tumor or cavernous malformations, the surgeon continuously received information about the surrounding tissue by constantly mapping with a stimulator aspirator. Changed his tactics depending on the data he received. Of course, this way probably can identify only efferent fibers III-VII $[27,45]$ and IX-XII [46, 47]. Thusly, upon received responses from motor fibers of cranial nerves such as V, VII and IX-X, should attention to one or the other reflexes for additional control of the afferent fibers $[27,48]$. Also, was recorded fEMG activity overwhelmingly like "spikes" or "bursts" during the iBSM. Control CoMEPs was hampered by peripheral activity during the first minutes, but when stop the stimulus and perform irrigation with warm solution, a control was possible. Just in the group $(n=9,21.4 \%)$ where was registered responses of 0.5 $\mathrm{mA}$ with activity fEMG of the type trains $\mathrm{A} / \mathrm{B} / \mathrm{C}$ as a result of surgical manipulations (traction, extraction, or coagulation) we got a decrease of amplitude CoMEPs more than 50\% and fixed of a new corresponding neurological deficit on discharge. With regard activity fEMG, we cannot assert a high selectivity due to the lack of automatic analysis system for fEMG "Ampel" [49], but that activity should keep in mind for the brainstem surgery.

Third step, when the neurosurgeon approached the potential long pathways, in consideration of the anatomical and functional features of the zone, we registered single activity of type spikes and bursts on fEMG [40] or single responses from distal muscles of upper and/or lower limbs. We changed the stimulation tactics - train-of-three and raised up intensity to 2 $\mathrm{mA}$ or not more than $4 \mathrm{~mA}$. After receiving a response, it was lowered, the minimal stimulus intensity was $0.5-1 \mathrm{~mA}$ for the response from contralateral extremities muscles. During stimulation, we recorded responses from the muscles of the distal limbs, with corresponding latency and shape. For midbrain, responses were obtained in the range of 1-3.5 mA, for pons and medulla oblongata $0.5-2 \mathrm{~mA}$. The technique of mapping the pathways is common for the patient where requires subcortical mapping of the corticospinal tracts in brain tumor surgery [51] and the described Ori Barzilai [50] upon mapping of the corticospinal tracts in intramedullary spinal cord tumor surgery. Of course, we cannot approve of for sure that we received the responses from the corticospinal tract, as we are not able to use intraoperative navigation for deeply located lesions [41]. All that responses have been obtained in cases with possible damage corticospinal tract, in view of the closely proximity lesions by preoperative MRI data [52]. Perhaps in some cases we received answers from medial lemniscus (long sensitive paths). Respectively, all these patients had intraoperative some changes TcMEPs after surgical manipulation in the range of response. But in the group $(n=13,30.9 \%)$ where was registered responses with intensive of 0.5-1 mA, was got a critical changes TcMEPs and SSEPs with decrease of amplitude more than 50\% and more than $10 \%$ lengthening of latency for SSEPs, with a new deficit on discharge (hemihypesthesia and/or hemiparesis).

The fact of received stable muscles responses integrated with cranial nerves/nuclei or distal extremities during surgical manipulations deep in the brainstem allowed to change not only in surgical tactics, also in IONM tactics, which, in turn, helped to strengthen the control and run down the risk of new/deepened deficit in our patients, increased the Karnofsky Performance Scale on last follow-up control in relation to the totality removal. As for BAEPs G. Polo [53] demonstrated BAEPs changes during microvascular decompression surgery with particular attention to lengthening latency of the $\mathrm{V}$ wave for preventing hearing losses, we lost the signal in two cases, but didn't get the expected deficit. Possibly with the new technique described by Andrea Szelényi [54] BAEPs will be more effective for the brainstem surgery. As for the gained experience in with reflexes, it is insufficient and require additional evaluation in the content, but can be used in brain stem surgery, like on-line monitoring for prediction new deficit.

\section{CONCLUSION}

1) TcMEPs and CoMEPs is reliable on-line techniques for the brainstem surgery. But it is recommended that it should preferably be performed at a frequency of 1-5 minutes, conditionally upon SSEPs and fEMG activity, by consider of the neurosurgeon's manipulation in the process, such as tissue traction and retraction, coagulation and last removal stage for the cavernous malformations. Abrupt, even transient changes below the critical level of TcMEPs, CoMEPs and SSEPs that follow after surgical manipulations demonstrate subsequent neurological deficit after surgery. By ignoring the change in tactics, it is way form a sustained change in these parameters with new or deepening permanent deficit.

2) The effectiveness of the use of "Intrinsic brainstem mapping" in brainstem surgery cannot be proven, as requires further processing data, more numbers of cases and subsequent upgrading.

3) Brainstem surgery has urgent necessity in development with modifications IONM for wider and more comfortable use by neurosurgeons.

\section{ACKNOWLEDGMENT}

None. 


\section{References}

[1] A. Bricolo, S. Turazzi, L. Cristofori, and A. Talacchi, "Direct surgery for brainstem tumours," Acta Neurochir. Suppl., vol. 53, pp. 148-158, 1991.

[2] R. Hoshide, V. Tardivo, and C. Teo, Keyhole approaches for deep-seated lesions, Randwick: NSW, 2019.

[3] A. Fonseca, and E. Bouffet, "Brainstem gliomas ... the devil is in the details," Neuro-Oncol., vol. 23, no. 6 pp. 869-871, 2021.

[4] C. Strauss, J. Romstock, C. Nimsku, and R. Fahlbusch, "Intraoperative identification of motor areas of the rhomboid fossa using direct stimulation," J. Neurosurg., vol. 79, pp. 393-399, 1993.

[5] A. T. Meybodi, and J. K. Liu, "Combined petrosal approach for resection of a large trigeminal schwannoma with Meckel's cave involvement-part I: anatomic rationale and analysis: 2-dimensional operative video," Oper. Neurosurg., vol. 20, no. 3, art. no. E225, 2021.

[6] E. Lefevre, P. Roblot, and M. Kalamarides, "Isolated bilateral hypoglossal palsy complicating a fourth ventricle ependymoma surgery," World Neurosurg., vol. 140, pp. $1-3,2020$.

[7] N. Morota, V. Deletis, M. Lee, and F. J. Epstein, "Functional anatomic relationship between brain stem tumors and cranial motor nuclei," Neurosurg., vol. 39 no. 4, pp. 787-794, 1996.

[8] S. G. Mueller, "Mapping internal brainstem structures using MP2RAGE derived T1 weighted and T1 relaxation images at 3 and 7," Human Brain Mapping., vol. 41 no. 8, pp. 2173-2186, 2020.

[9] Y. Yang, B. Niftrik, X. Ma, J. Velz, S. Wang, L. Regli, and O. Bozinov, "Analysis of safe entry zones into the brainstem," Neurosurg. Rev., vol. 42, no.3, pp. 721-729, 2019.

[10]F. Sala, M. J. Kržan, and V. Deletis, "Intraoperative neurophysiological monitoring in pediatric neurosurgery: Why, when, how?" Child's Nerv. Sys., vol. 18, pp. 264287, 2002.

[11] T. Sekiya, T. Hatayama, T. Iwabuchi, and S. Maeda, "Intraoperative recordings of evoked extraocular muscle activities to monitor ocular motor nerve function," Neurosurg., vol. 32, no. 2, pp. 227-235, 1993.

[12] J. W. House, and D. E. Brackmann, "Facial nerve grading system," Otolaryngol.-Head Neck Surg., vol. 93, no. 2, pp. 146-147, 1985.

[13] K. H. O'Neil, M. Purdy, J. Falk, and L. Gallo, "The dysphagia outcome and severity scale," Dysphagia, vol. 14, pp. 139-145, 1999.

[14]P. C. McCormick, R. Torres, K. D. Post, and B. M. Stein, "Intramedullary ependymoma of the spinal cord," J. Neurosurg., vol. 72, pp. 523-532, 1990.

[15]D. A. Karnofsky, W. H. Abelmann, L. F. Craver, and J. H. Burchenal, "The use of nitrogen mustards in the palliative treatment of carcinoma," Cancer, vol. 1, pp. 634-656, 1948

[16] A. Chaudhary, "Cresentic durotomy for midline posterior fossa lesions," Neurol. India, vol. 67, no. 1, 2019.
[17]A. J. Sabbagh, and A. M. Alaqeel, "Focal brainstem gliomas. Advances in intraoperative management," Neurosci., vol. 20, no. 2, pp. 98-106, 2015.

[18] M. R. Nuwer, "Laryngeal reflex testing during posterior fossa surgery: Assessing vagus sensory and motor pathways," Clin. Neurophys., vol. 132, no. 2, 2021.

[19] P. J. Slotty, A. Abdulazim, K. Kodama, M. Javadi, D. Hänggi, V. Seifert, and A. Szelényi, "Intraoperative neurophysiological monitoring during resection of infratentorial lesions: The surgeon's view," J. Neurosurg., vol. 126, no. 1, pp. 281-288, 2017.

[20]K. Majchrzak, B. Bobek-Billewicz, A. Hebda, H. Majchrzak, P. Ładzińs i, and L. Krawczyk, "Surgical treatment and prognosis of adult patients with brainstem gliomas," Neurolog. Neurochir. Polska, vol. 52, no. 5, pp. 623-633, 2018.

[21]F. Sala, P. Manganotti, V. Tramontano, A. Bricol, and M. Gerosa, "Monitoring of motor pathways during brain stem surgery: What we have achieved and what we still miss?" Clin. Neurophys., vol. 37, no. 6, pp. 399-406, 2007. doi:10.1016/j.neucli.2007.09.013.

[22] G. Neuloh, J. Bogucki, and J. Schramm, "Intraoperative preservation of corticospinal function in the brainstem," $\mathrm{J}$. Neurolog., Neurosurg., Psychiatry, vol. 80, no. 80, pp. 417-422, 2009.

[23]D. B. MacDonald, C. Dong, R. Quatrale, F. Sala, S. Skinner, F. Soto, and A. Szelényi, "Recommendations of the International Society of Intraoperative Neurophysiology for intraoperative somatosensory evoked potentials," Clin. Neurophys., vol. 130, pp. 161179, 2019.

[24] L. Xuesong, Yu. Zhang, X. Hui, Ch. You, F. Yuan, W. Chen, and S. Zhang, "Surgical management of medulla oblongata hemangioblastomas in one institution: an analysis of 62 cases," Int. J. Clin. Exp. Med., vol. 8, no. 4, pp. 5576-5590, 2015.

[25] V. Deletis, I. Fernández-Conejero, S. Ulkatan, M. Rogic, E. Lladó Carbó, and D. Hiltzik, "Methodology for intraoperative recording of the corticobulbar motor evoked potentials from cricothyroid muscles," Clin. Neurophys., vol. 122, no. 9, pp. 1883-1889, 2011.

[26] T. Kanbayashi, and M. Sonoo, "The course of facial corticobulbar tract fibers in the dorsolateral medulla oblongata," BMC Neurol., vol. 21, no. 1, 2021.

[27] J. F. R. Paton, "Clarity of the rhythmic brainstem," J. Clin. Neurolog., vol. 598, no. 11, pp. 2045-2046, 2020.

[28] S. M. Verst, A. C. Sucena, M. V. Maldaun, and P. H. Aguiar, "Effectiveness of $\mathrm{C} 5$ or $\mathrm{C} 6-\mathrm{Cz}$ assembly in predicting immediate post operative facial nerve deficit," Acta Neurochir., vol. 155, pp. 1863-1869, 2013.

[29] M. Fukuda, M. Oishi, T. Takao, N. Saito, and Y. Fujii, "Facial nerve motor-evoked potential monitoring during skull base surgery predicts facial nerve outcome," J. Neurol., Neurosurg., Psychiatry, vol. 79, no. 9, pp. 10661070, 2008.

[30] R. F. Hardian, T. Goto, Y. Fujii, K. Kanaya, T. Horiuchi, and K. Hongo, "Intraoperative facial motor evoked potential monitoring for pontine cavernous malformation 
resection,” J. Neurosurg., vol. 132, no. 1, pp. 265-271, 2019.

[31] N. Jerath, and J. Kimura, "F wave, A wave, H reflex, and blink reflex," Handbook Clin. Neurol., vol. 160, pp. 225239, 2019.

[32] J. Valls-Sole, "Spontaneous, Voluntary, and Reflex Blinking in Clinical Practice," J. Clin. Neurophys., vol. 36, no. 6, pp. 415-421, 2019.

[33]C. F. Sinclair, M. J. Téllez, O. R. Tapia, S. Ulkatan, and V. Deletis, "A novel methodology for assessing laryngeal and vagus nerve integrity in patients under general anesthesia," Clin. Neurophys., vol. 128, no. 7, pp. 13991405, 2017.

[34] M. A. Sanchez-Roldan, M. J. Tellez, S. Ulkatan, and C. F. Sinclair, "Continuous vagal neuromonitoring using the laryngeal adductor reflex: Can preincision dyssynchrony predict intraoperative nerve behavior?" Otolaryngology Head Neck Surg., vol. 161, no. 1, pp. 118-122, 2019.

[35]A. D. Legatt, "Electrophysiologic auditory tests," Handbook Clin. Neurol., vol. 129, pp. 289-311, 2015.

[36] American Clinical Neurophysiology Society, "Guideline 9C: Guidelines on short- latency auditory evoked potentials," J. Clin. Neurophys., vol. 23, no. 2, pp. 157$167,2006$.

[37]H. Takami, C. S. Graffeo, A. Perry, C. Giannini, and D. J. Daniels, "The third eye sees double: cohort study of clinical presentation, histology, surgical approaches, and ophthalmic outcomes in pineal region germ cell tumors," World Neurosurg., vol. 150, pp. e482-e490, 2021.

[38] A. M. Pescador, M. Angeles Sanchez Roldan, M. J. Tellez, C. F. Sinclair, and S. Ulkatan, "Unforeseen clinical outcome for laryngeal adductor reflex loss during intraaxial brainstem surgery," Clin. Neurophys., vol. 130, no. 10, pp. 2001-2002, 2019.

[39]L. C. Jameson, and T. B. Sloan, "Neurosurgical anesthesia. Neurophysiologic monitoring in neurosurgery," Anesthes. Clin., vol. 30, pp. 311-331, 2012.

[40] J. Romstöck, C. Strauss, and R. Fahlbusch, "Continuous electromyography monitoring of motor cranial nerves during cerebellopontine angle surgery," J. Neurosurg., vol. 93 , no. 4, pp. 586-593, 2000.

[41] S. Gui, G. Me, X. Xiao, Zh. Wu, and J. Zhang, "Surgical management of brainstem cavernous malformation: Report of 67 patients," World Neurosurg., vol. 122, pp. 1162-1171, 2019.

[42]D. D. Cavalcanti, M. C. Preul, M. Y. Kalani, and R. F. Spetzler, "Microsurgical anatomy of safe entry zones to the brainstem," J. Neurosurg., vol. 124, pp. 1359-1376, 2016.

[43] K. Yagmurlu, M. Y. S. Kalani, M. C. Preul, and R. F. Spetzler, "The superior fovea triangle approach: A novel safe entry zone to the brainstem," J. Neurosurg., vol. 127, pp. 1134-1138, 2017.

[44] L. Zhibao, M. Wang, L. Zhang, X. Fan, X. Tao, L. Qi, M. Ling, X. Xiao, Yu. Wu, D. Guo, and H. Qiao, "Neuronavigation - guided corticospinal tract mapping in brainstem tumor surgery: better preservation of motor function," World Neurosurg., vol. 116, pp. 291-297, 2018.

[45]P. Hariharan, J. R. Balzer, K. Anetakis, D. J. Crammond, and P. D. Thirumala, "Electrophysiology of extraocular cranial nerves: Oculomotor, trochlear, and abducens nerve," J. Clin. Neurophys., vol. 35, pp. 11-15, 2018.

[46] S. Y. Kim, H. W. Im, Y.-D. Choi, K. Kim, J. W. Kim, Y. H. Kim, and H. G. Seo, "Intraoperative monitoring of hypoglossal nerve using hypoglossal motor evoked potential in infratentorial tumor surgery: A report of two cases," Annals Rehab. Med., vol. 42, no. 2, pp. 352-357, 2018.

[47] S. Gläsker, U. Pechstein, V. I. Vougioukas, and V. V. Velthoven, "Monitoring motor function during resection of tumours in the lower brain stem and fourth ventricle," Child's Nerv. Sys., vol. 22, pp. 1288-1295, 2006.

[48]F. Sala, "A spotlight on intraoperative neurophysiological monitoring of the lower brainstem," Clin. Neurophys., vol. 128, no. 7, pp. 1369-1371, 2017.

[49] J. Prell, C. Strauss, S. K. Plontke, and S. Rampp, "Intraoperative monitoring of the facial nerve. Vestibular schwannoma surgery," HNO, vol. 65 , no. 5, pp. 404-412, 2017.

[50]A. Raabe, J. Beck, P. Schucht, and K. Seidel, "Continuous dynamic mapping of the corticospinal tract during surgery of motor eloquent brain tumors: evaluation of a new method," J. Neurosurg., vol. 120, pp. 10151024, 2014.

[51]O. Barzilai, Z. Lidar, Sh. Constantini, Kh. Salame, Y. Bitan-Talmor, and A. Korn, "Continuous mapping of the corticospinal tracts in intramedullary spinal cord tumor surgery using an electrified ultrasonic aspirator," J. Neurosurg., vol. 27, pp. 161-168, 2017.

[52] Yu. Tanga, W. Suna, A. W. Toga, J. M. Ringmanc, and Y. Shia, "A probabilistic atlas of human brainstem pathways based on connectome imaging data," Neurolmag., vol. 169, pp. 227-239, 2018.

[53] G. Polo, C. Fischer, M. P. Sindou, and V. Marneffe, "Brainstem auditory evoked potential monitoring during microvascular decompression for hemifacial spasm: Intraoperative brainstem auditory evoked potential changes and warning values to prevent hearing lossprospective study in a consecutive series of 84 patients", Neurosurg., vol. 54, pp. 97-104, 2004.

[54]T. Greve, F. Beyer, and A. Szelényi, "Intraoperative Erb's Point-Vertex recording increases brainstem auditory evoked potential wave V amplitude," Clin. Neurophys., vol. 131, pp. 420-424, 2020.

\section{Author Contributions:}

Volodymyr I. Smolanka: Conceptualization, Investigation, Formal analysis and Writing - original draft.

Andrey V. Smolanka: Investigation, Formal analysis and Writing - original draft and Writing - review \& editing. Oleksandr S. Sechko: Investigation, Formal analysis and Writing - original draft and Writing - review \& editing. 
Olga S. Herasymenko: Investigation, Formal analysis and Writing - original draft and Writing - review \& editing.

Creative Commons Attribution License 4.0 (Attribution 4.0 International , CC BY 4.0)

This article is published under the terms of the Creative Commons Attribution License 4.0

https://creativecommons.org/licenses/by/4.0/deed.en_US 